\title{
ELECTRICAL INSULATION CHALLENGES FOR ROTATING MACHINES USED ON FUTURE ELECTRIC SHIPS
}

By:

R.E. Hebner

28th Electrical Insulation Conference, held in conjunction with $2007 \mathrm{EIC/Electrical} \mathrm{Manufacturing}$ Expo (2007 EIC/EMExpo), Nashville, Tennessee, U.S.A., October 22-24, 2007.

PR 475

Center for Electromechanics

The University of Texas at Austin

PRC, Mail Code R7000

Austin, TX 78712

(512) 471-4496 


\title{
Electrical Insulation Challenges for Rotating Machines Used on Future Electric Ships
}

\author{
R.E. Hebner \\ University of Texas at Austin \\ Center for Electromechanics \\ 1 University Station \#R7000 \\ Austin, Texas 78712 USA
}

\begin{abstract}
The electrification of ships coupled with a demand for very high power and energy density raises challenges for insulation system designers for this market. The physical reason the design is challenging is that the electrical, mechanical, and thermal environment on a ship is sufficiently far from the land-based environment that key parts of the data and experience base needed for insulation system design do not exist.
\end{abstract}

\section{INTRODUCTION}

Commercial and military ships are becoming more electric. This move toward electrification is driven by requirements for higher power density. The desire for higher power density results from a need to have flexibility to use the space in the hull more effectively. For commercial ships, this is motivated by a push to maximize revenue. For military ships, the motivation is to provide more space to carry mission critical components. In no case, is the power system the motivation for the ship. So, while the power system is critical, there are financial and policy reasons to make it as small as possible.

At the same time, the demand for shipboard power is increasing. The largest demand on an electric ship is typically for propulsion. Other loads, however, such as heating, cooling, navigation, communication, and, for warships, weapon systems, are also increasing power demand. In fact, it is anticipated that moderate-sized ships in the future will require power systems that are capable of providing possibly as much as $100 \mathrm{MW}$.

Since a ship at sea is not connected to a power grid, it must guarantee its own reliability. Thus, it must have redundant generators. If reliability did not require multiple generators, fuel economy would. While the peak load may approach $100 \mathrm{MW}$, a ship at anchor may require less than 5 MW. It would not be efficient to provide power for both of these with a single prime mover.

For electric ships, the prime mover of choice is increasingly a gas turbine. These are smaller and lighter than diesel engines for the same power level. They also have the characteristic, shown in Fig. 1, that the maximum optimum speed varies with power level [1].

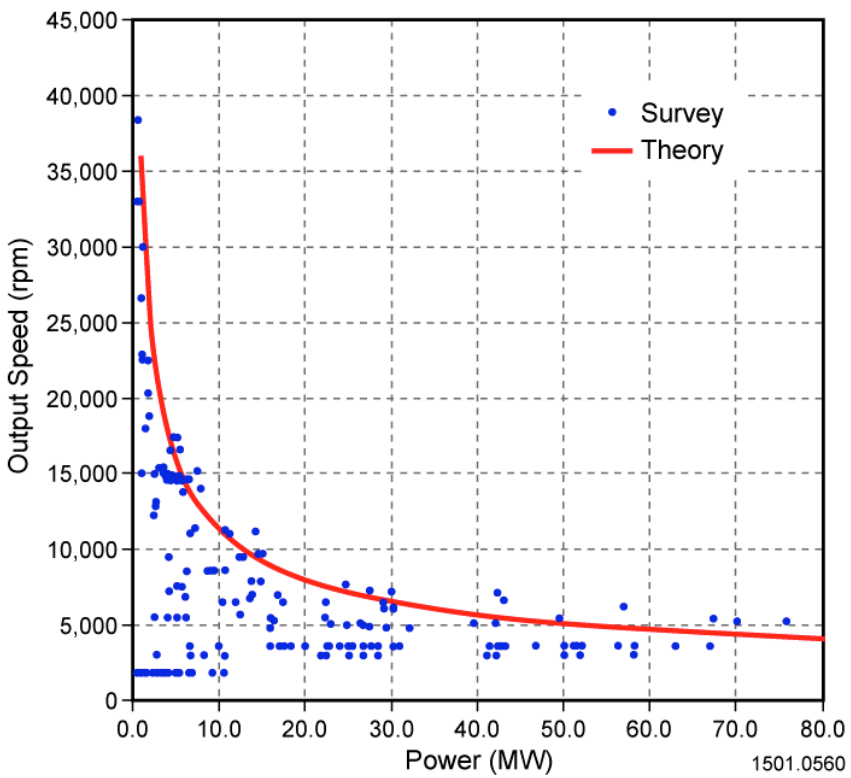

Figure 1. The solid line is the theoretical speed-power curve for gas turbines and the points are manufacturers' published specifications.

The turbine power ratings for electric ships tend to range between $1 \mathrm{MW}$ and $40 \mathrm{MW}$, depending on the specific ship. As seen in Fig. 1, this is a portion of the curve in which the turbine speed changes rapidly with a change in power.

The conventional approach has been to use a gear box on the output of the various gas turbines. In this way, the turbines can run at the appropriate speed to achieve maximum efficiency and the attached generators can all turn at the same speed and produce electricity at a conventional power frequency, i.e., $50 / 60 \mathrm{~Hz}$. This tends not to be a power dense approach.

To achieve improved power density, efforts are underway to replace the gearbox with power electronics. In principle, with power electronics, one can convert any input waveform to dc then to whatever voltage and frequency level needed within the limits of available power.

\section{IMPLICATIONS FOR INSULATION}

The obvious implication of a push for higher power and energy density for electrical insulation is that one would want to use the smallest amount of insulation possible for reliable operation. The environment adds nuance to this requirement, however. The process of specifying an 
electrical insulation system was summarized by Murase, et al. [2]. The approach is summarized in Fig. 2.

This figure highlights the fact that there are two fundamental aspects to a successful design of an insulation system. First, the designer must have good information concerning the properties of the insulating materials. Second, there must also be good information available concerning the operating environment, frequently involving experience in that environment.

These two design requirements underscore a challenge for the insulation system designer for future electric ships. This challenge arises because the preponderance of the information that is available on the properties of electrical insulation is relevant for land-based systems. While the information developed over decades of information and experience with land-based systems provides an excellent foundation for the future electric ship, it is not complete.

Some of the key differences include:

- The land-based power gird is an antenna for lightning pulses and key components are tested to ensure they can withstand standard lightning impulses. Being in a grounded imperfect Faraday cage, ship power systems are expected to have different lightning exposure than land-based systems.

- Land-based components are typically tested for immunity to standard switching surges. The ship has a closely coupled power system, so a very different type of switching surge is expected.

- The demand for increased power and energy density for ships encourages the use of high speed or superconducting solutions for rotating machines. This leads to mechanical and thermal stresses that are not common in land-based systems.

- Different system impedances lead to different relationships between voltage and current harmonics in land-based and shipboard systems.

- Electrical frequencies at which power is generated or delivered range between dc and several hundred Hz on ships.

- Typically, ship systems are expected to have shorter lifetimes than land-based systems.

These differences can be significant. For example, for cables and transformers, the standard system test producing the highest electric field [2] is the lightning impulse breakdown test. With the very different environment on a ship, designing to pass the conventional tests may produce an insulation system that is too large, too small, or optimized for the wrong frequencies.

\section{Cryogenic Systems}

Because of their potential for producing power density by producing a large air-gap magnetic field, cryogenic motors and generators are being developed for marine applications. Systems under consideration include low-temperature superconducting systems [3], wound-rotor high-temperature machines [4], and trapped-field machines that show promise to produce the highest air gap fields and operate at higher temperature [5].

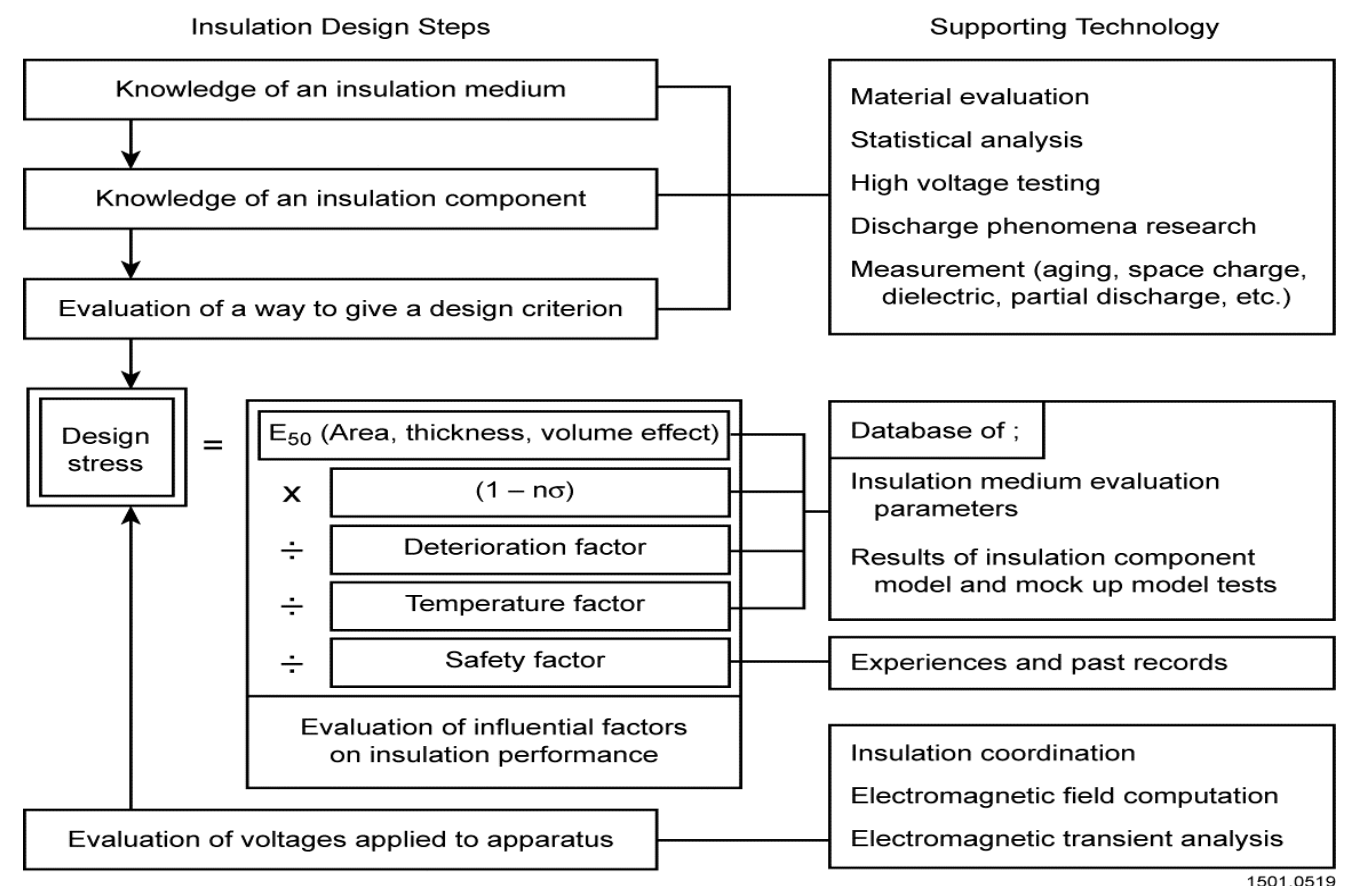

Figure 2. Summary of design process for insulation system. 
The obvious concern with cryogenic operation is whether an insulating system will work as intended at cryogenic temperatures. Fortunately, many materials work better at lower temperatures. The next largest concern is the integrity of the insulation system over the large thermal excursion whenever the system is cycled between room temperature and operating temperature. To design these systems, significant information is needed on the material coefficients of thermal expansion over ranges of little interest for land-based systems.

There are additional important considerations, however. Because the high magnetic field saturates available magnetic steels, for example, these motors and generators operate much like air-core machines. While the windings on the rotor are shielded from mechanical forces by an eddy current shield [6], the stator windings will experience mechanical forces. The stator insulation system must manage the forces seen by the windings without compromising its ability to provide electrical insulation.

\section{High SPEED GENERATORS}

A second approach to increasing energy density in rotating machines is to increase the rotational frequency. This is an approach that is being considered for generators. For motors, operating the motor at the required speed is usually the more energy dense solution than operating the motor at high speed and using a gear box to reduce the speed to the required range.

Generators initially tended to have wound rotor designs, although permanent magnet high-speed generators are under development [7]. Two of the challenges faced by permanent magnet solutions are the inability to turn them off to avoid exacerbating a stator fault, and concerns of lifetime in an environment of high current surges coupled with significant shock and vibration. But these are not insulation problems.

Insulation issues arise when a wound rotor is used at high speed. High speed, in this context, means high tip speed. For high tip speed, the rotor grows when the rotor is brought to operating speed and shrinks when brought back to rest. With the conventional materials used in rotors, this change in geometry can be sufficient to compromise an insulation system, particularly if attention to growth matching is not part of the initial design.

Perhaps more challenging is that high speed generators operate at frequencies above the $50 / 60 \mathrm{~Hz}$ found in conventional machines. The losses in magnetic materials scale as the square of the electrical frequency. So, without aggressive cooling, the temperature is higher and the insulation life is shortened.

A final challenge to be highlighted is that, in some cases, manufacturers rate the safe operating temperature of an insulating material above its glass transition temperature. While this practice may be acceptable for stator insulation at moderate and low air gap fields, it can cause problems whenever there is significant mechanical stress on the conductors and the insulation system.

\section{MOTORS}

A significantly studied implication, for motors, of the evolving electrical environment is the role of the stress reducing grading [8] at the ends of the slot in the stator. These gradings make testing or operation problematic at dc [8], with high harmonics [9] in a line connected situation, and at high frequencies [10], as seen from inverter switching. Given the wide range of potential environments, it is unlikely that there will be a general solution to this problem. Rather, it is more likely that the designer will optimize the stress grading to meet the conditions of the targeted electrical environment.

A second issue of motors has to do with thermal management. Since ships have chillers available, a designer might consider using a coolant that is significantly below room temperature to permit a greater current density without changing the insulation system, thus increasing power density. This can be made to work. It is, after all, a key component in cryogenic systems. It requires significant engineering, however, as it reduces margin. Small variations in cooling efficiency can lead to catastrophic failure.

\section{CONCLUSIONS}

The ship power system operates in an environment that is different enough from the norm to stimulate some action. The following areas are among those that merit attention:

- Standards used for land-based insulation systems are not likely to provide good guidance for ship insulation system design. In general, standards codify experiences, a key design component, as indicated in Fig. 2. The standards developers tend to have significant experience in land-based applications, but not in the marine environment.

- There is a need to specify the electrical, thermal, and mechanical environment that a ship power system will experience and to determine how well that environment has been explored by existing materials research and standard tests. Component suppliers will continue to be plagued with problems until this situation is rectified.

\section{ACKNOWLEDGEMENT}

This work was supported by the Office of Naval Research. The author thanks A. Ouroua, K. Davey, J. Herbst, A. Wilder, and H. Jordan for many informative discussions on the topics summarized in this paper

\section{REFERENCES}

[1] S. Vijlee, A. Ouroua, L. Domaschk, and J. Beno, "Directly coupled gas turbine permanent magnet generator sets for prime power generation on board electric ships," IEEE Electric Ship Technologies Symposium, Arlington, Virginia, U.S.A., May 21-23, 2007. 
[2] H. Murase, et al., "Systematization of insulation design technology for various electric power apparatus," IEEE Trans. Dielectr. Electr. Insul., vol. 13, pp. 400-407, 2006.

[3] P. Barnes, M. Sumption, and G. Rhodes, "Review of high power density superconducting generators: present state and prospects for incorporating YBCO windings," Cryogenics, vol. 45, pp. 670-686, 2005.

[4] G. Snitchler, B. Gamble, and S. Kalsi, "The performance of a 5 MW high temperature superconductor ship propulsion motor," IEEE Trans. Appl. Supercon., vol. 15, pp. 2206-2209, 2005.

[5] R. Weinstein, R. Sawh, and A. Crapo, "An experimental generator using high temperature superconducting quasi-permanent magnets," IEEE Trans. Appl. Supercon., vol. 5, pp. 441-444, 1995.

[6] J. Edick, R. Schiferl, and H. Jordan, "High temperature superconductivity applied to electric motors," IEEE Trans Appl. Supercon., vol. 2, pp. 189-194, 1992.
[7] O. Aglen, "Loss calculation and thermal analysis of a high-speed generator," Electric Machines and Drives Conf., vol. 2, pp. 1117$1123,2003$.

[8] A. Roberts, "Stress grading for high voltage motor and generator coil," IEEE Electr. Insul. Mag., vol. 11, pp. 26-31, 1995.

[9] R. Hebner, H. El-Kishky, M. Abdel-Salam, and F. Brown, "Higher frequency performance of stress-grading systems for HV large rotating machines," Conf. Electr. Insul. and Dielectr. Phenom., pp. 218-221, 2006.

[10] F. Espino-Cortes, E. Cherney, and S. Jayaram "Effectiveness of stress grading coatings on form wound stator coil groundwall insulation under fast rise time pulse voltages," IEEE Trans. Energy Conversion, vol. 20, pp. 844-851, 2005. 